THIAGO MAASS STEINER

\title{
PAPEL DA PROTEÍNA ALVO DA RAPAMICINA (MTOR) NAS VIAS METABÓLICAS E FUNÇÕES EFETORAS DE CÉLULAS B
}

Dissertação apresentada ao Programa de Pós-Graduação em Imunologia do Instituto de Ciências Biomédicas da Universidade de São Paulo para obtenção do título de Mestre em Ciências

Área de concentração: Imunologia

Orientador: Prof. Dr. Niels Olsen Saraiva Câmara

Versão original

SÃO PAULO

2017 


\section{RESUMO}

Steiner TM. Papel da proteína alvo da Rapamicina (mTOR) nas vias metabólicas e funções efetoras de células B. [Dissertação (Mestrado em Imunologia)]. São Paulo: Instituto de Ciências Biomédicas, Universidade de São Paulo; 2018

As células produtoras de anticorpos desempenham um papel chave na resposta efetora a microrganismos, sendo o foco principal da maioria das vacinas existentes. Entretanto, elas podem ter efeitos deletérios em doenças autoimunes e na rejeição a transplantes. Apesar de grandes avanços no controle da resposta humoral, alguns desafios permanecem e neste contexto, novos alvos terapêuticos têm sido explorados. Sabe-se que alterações metabólicas decorrentes da ativação de células B estão intimamente relacionadas com a função efetora destas células, o que anteriormente se imaginava ser apenas um reflexo de crescimento e proliferação celular. Estas alterações são controladas por sensores metabólicos ativados logo após a ativação de células B, como o mTOR, o qual é componente central de dois complexos: mTORC1 e mTORC2. Estudos anteriores já reportaram o papel positivo exercido por mTOR na via glicolítica em células T, bem como na função efetora destas células. Aqui, nós formulamos a hipótese de que a via do mTOR favorece a via glicolítica em detrimento de OXPHOS em células B, e que estas alterações metabólicas impactam as funções efetoras das mesmas. Desta maneira, para investigarmos alterações nestas vias em decorrência de mTOR, células B foram isoladas de animais controle (CT), ou de animais com células B deficientes de mTORC1 (Raptor ${ }^{\triangle \mathrm{B}}$ ) ou mTORC2 (Rictor ${ }^{\triangle \mathrm{B}}$ ) e então estimuladas com LPS (lipopolissacarídeo) in vitro. Nossos dados indicam que a deficiência de mTORC2 beneficia OXPHOS em detrimento da via gicolítica, bem como a ativação de células B e a formação de plasmablastos. Na sequência, confirmamos que a redução nas taxas de glicólise, assim como a elevação da oxidação lipídica e de OXPHOS são cruciais para manter a elevada ativação de células $B$ e formação de plasmablastos a partir de células B Raptor ${ }^{\triangle B}$ e Rictor ${ }^{\Delta B}$. Constatouse ainda que a produção total de IgM é elevada em células Rictor ${ }^{\triangle B}$ após estímulo com LPS. Entretanto, identificamos que isso é decorrente do aumento de plasmablastos formados e não da capacidade individual de secreção dos mesmos. Diferentemente das células B deficientes, observamos que plasmablastos Raptor $^{\triangle \mathrm{B}}$ e Rictor ${ }^{\triangle \mathrm{B}}$ reduzem a atividade mitocondrial. Na sequência, confirmamos que a atividade mitocondrial via oxidação lipídica é fundamental para a produção de anticorpos. Além disso, demonstramos que a deficiência de mTORC2 eleva a troca de isotipo, enquanto a de mTORC1 a diminui após estimulo com LPS e IL4. Posteriormente, o impacto da deficiência de mTORC2 em células B foi avaliado in vivo em modelo de transplante de pele. Neste caso, não observamos diferenças significativas na sobrevida do enxerto entre CT e Rictor ${ }^{\triangle \mathrm{B}}$, mas foi constatado que apesar de ambos apresentarem formação de plasmócitos similares, animais deficientes apresentaram um número significativamente menor de células B na periferia. Assim, concluímos que a deficiência de mTORC1 ou mTORC2 em células B implica em uma maior diferenciação de plasmablastos e em uma maior produção total de anticorpos em Rictor ${ }^{\Delta \mathrm{B}}$ in vitro, enquanto um papel funcional para essas moléculas no contexto das células B in vivo ainda precise ser determinado.

Palavras-chave: Plasmablastos. Plasmócitos. Células B. mTOR. Vias metabólicas. 


\begin{abstract}
Steiner TM. Role of the Mechanistic Target of Rapamycin (mTOR) on metabolic pathways and effector function of B cells. [Dissertação (Mestrado em Imunologia)]. São Paulo: Instituto de Ciências Biomédicas, Universidade de São Paulo; 2018.

Antibodies are produced by Antibody Secreting Cells (ASCs), which are essential to fight infections. They are also the basis of most successful vaccines available, however they can present deleterious effects in autoimmune diseases and in graft rejection. Even though there have been great improvements in controlling the humoral response, its proper manipulation still remains a challenge, thus new targets need to be explored. It is known that metabolic shifts that occur upon B cell activation are not only essential for cell growth and proliferation, but are also interconnected with these cells effector function. Metabolic shifts are controlled by metabolic sensors, as the mTOR, which is a core component of two complexes, mTORC1 and mTORC2. Previous studies with T cells have already reported that mTOR exerts a positive role on glycolysis, which in turn impacts the effector function of $\mathrm{T}$ cells. We then hypothesized that mTOR favors glycolysis over Oxidative Phosphorylation (OXPHOS) in B cells, and that these metabolic changes impact the effector function of B cells. Thus, to investigate the impact of the mTOR pathway on B cells, we isolated B cells from mice with mTORC1 deficient $\mathrm{B}$ cells (Raptor ${ }^{\triangle \mathrm{B}}$ ) or mTORC2 deficient $\mathrm{B}$ cells (Rictor ${ }^{\triangle \mathrm{B}}$ ) or Control mice (CT), and stimulated them in vitro with lipopolysaccharide (LPS). Our results indicate that the deficiency of mTORC2 favors OXPHOS over glycolysis, as well as B cell activation markers expression and plasmablast formation. Next, we confirmed that the reduced glycolysis levels, improved lipid oxidation and OXPHOS are in fact crucial for the enhanced activation and plasmablast formation observed in Raptor ${ }^{\triangle \mathrm{B}}$ and Rictor ${ }^{\triangle \mathrm{B}} \mathrm{B}$ cells. We also described that IgM secretion was elevated in B cells from Rictor ${ }^{\triangle B}$ after stimuli with LPS, however we found that this increase was due to the overall increase in plasmablasts in this group and not to their individual antibody secretion capacity. Interestingly, Raptor ${ }^{\triangle B}$ and Rictor ${ }^{\triangle B}$ plasmablasts differently from $B$ cells, reduce their mitochondrial activity. Subsequently, we confirmed that the mitochondria via lipid oxidation is actually essential for antibody secretion. In addition, we showed that mTORC2 deficiency increases isotype switching, while mTORC1 deficiency diminishes it when IL4 was added to LPS. We then sought to determine if mTORC2 deficiency in B cells would present an impact in vivo in a skin graft model. However, we did not observe a significant difference in graft survival between the CT and Rictor ${ }^{\triangle B}$ mice and in plasmacyte numbers, but we did observe a significant reduction in B cells in the periphery. Thus, we conclude that mTORC1 and mTORC2 deficiency leads to an improved plasmablast differentiation and an overall increase in antibody secretion in the last one in vitro, whereas the role of these sensors remains to be determined in vivo.
\end{abstract}

Key words: Plasmablasts. Plasmocytes. B cells. mTOR. Metabolic pathways. 


\section{INTRODUÇÃO}

A produção de anticorpos é fundamental na resposta a inúmeros microrganismos e mecanismo de ação de grande parte das vacinas existentes. Por outro lado, a resposta humoral pode representar uma ameaça como no contexto de doenças autoimunes, tais como lúpus sistêmico eritematoso e artrite reumatoide, bem como na rejeição a transplantes (1-3) .

Anticorpos são produzidos por células B diferenciadas em células produtoras de anticorpos, sendo estas compostas por plasmablastos e plasmócitos (4). Plasmablastos, assim como células $\mathrm{B}$, apresentam capacidade migratória, bem como de divisão e diferenciação em plasmócitos, os quais são caracterizados pela grande produção de anticorpos e por perderem as demais capacidades citadas (4).

Células B são geradas a partir de células B imaturas na medula óssea e terminam seu processo de maturação no baço, onde adquirem a expressão de IgD em sua membrana (4). As células B podem ser categorizadas em células B1 e células B2, sendo esta última subdividida em células B foliculares (célula B FO) e células B da Zona Marginal (célula B MZ) (4). Células B1 estão localizadas na cavidade pleural e peritoneal e em mucosas, já as células B MZ estão situadas no seio marginal do baço. A localização destas duas populações permite uma resposta rápida a patógenos circulantes (5). Por outro lado, células B FO compõem o subtipo predominante e estão localizadas nos folículos linfoides de linfonodos e baço (5). Estas células respondem predominantemente a antígenos proteicos capazes de

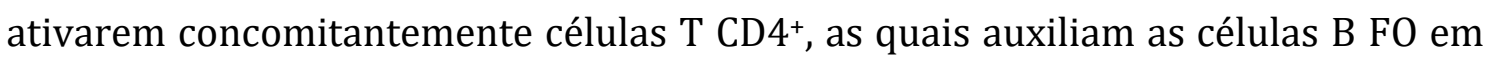
uma resposta conhecida como T-dependente (4). A resposta a antígenos Tdependentes ocorre em dois passos: em um primeiro momento, sem a contribuição de células $\mathrm{T} \mathrm{CD}^{+}$, ocorre a rápida formação de plasmócitos de vida curta e é conhecida como resposta extra-folicular (6). No estágio subsequente, algumas das células previamente ativadas reentram o folículo por meio da orientação de células T Foliculares ( $\left.\mathrm{T}_{\mathrm{FH}}\right)$, o que leva a ativação da enzima de ativação induzida citidina deaminase (AID, do inglês activation-induced cytidine deaminase) nestas células, responsável pela troca de isotipo (CSR, do inglês Class Switch Recombination) e hipermutação somática (HS, do inglês Somatic Hypermutation). No folículo estas células passam por intensa proliferação e são constantemente selecionadas para o 
aumento da afinidade ao antígeno após o processo de HS (Figura 1). Como produto final são gerados plasmócitos de vida longa, capazes de produzirem constantemente altos níveis de anticorpos, e células $\mathrm{B}$ de memória, capazes de proliferarem rapidamente e se diferenciarem em plasmócitos após reencontro com seu antígeno cognato $(4,7)$ (Figura 1).

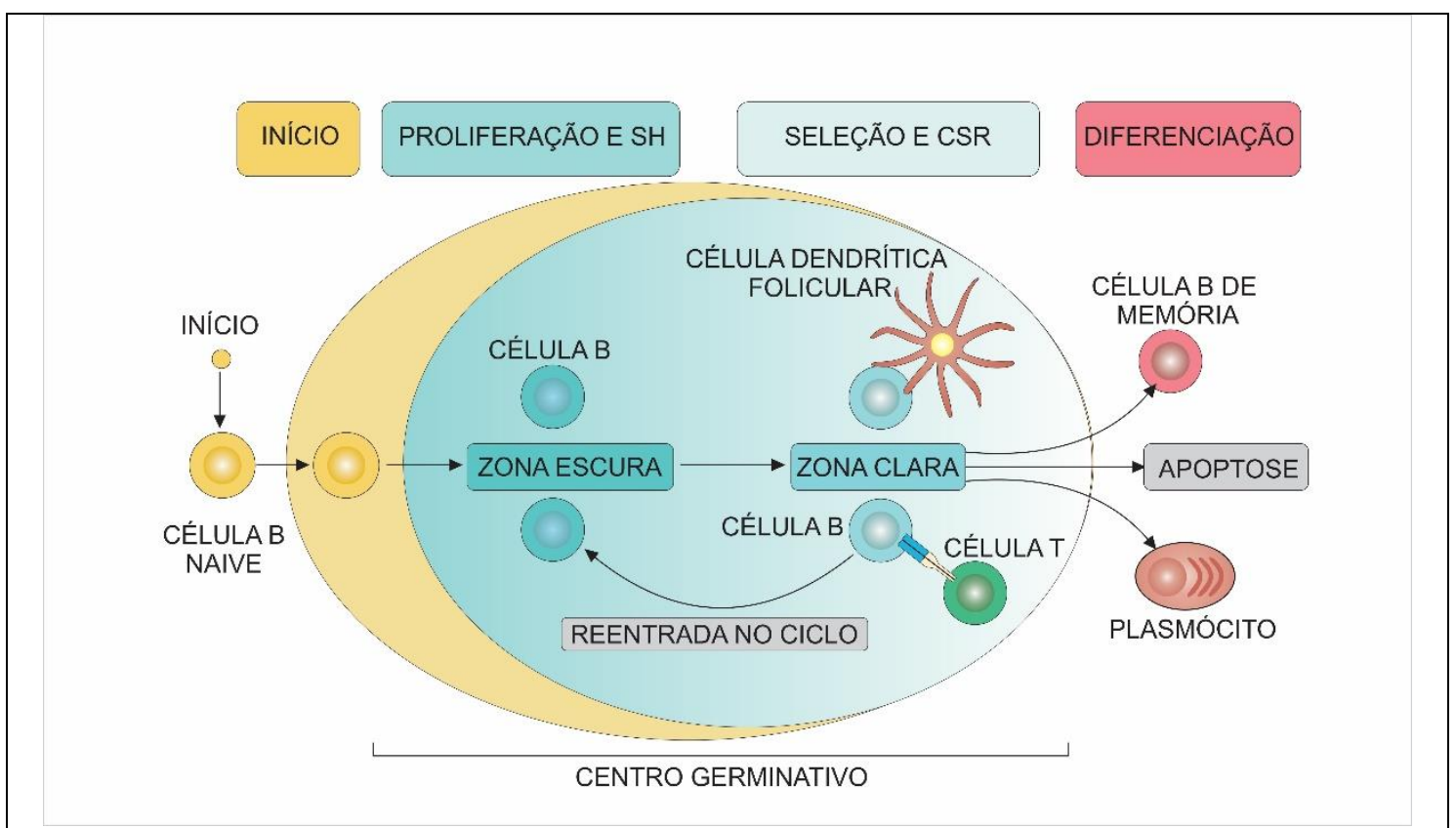

Figura 1 - Ativação de células B T-dependente. Após reconhecimento do antígeno, células B são ativadas e migram para fora do folículo, onde podem proliferar rapidamente. Entretanto, algumas das células B recém ativadas podem retornar ao folículo (região azul) por meio do auxílio de células $\mathrm{T}_{\mathrm{FH}}$. No folículo, células B passam por intensa proliferação (região azul escura) e pelos processos de HS e CSR, sendo assim selecionadas por afinidade ao antígeno. Desta maneira as células que não foram capazes de aumentar a afinidade ao antígeno entram em apoptose por não conseguirem competir pelos sinais de sobrevivência (região azul claro). Células B com alta afinidade ao antígeno podem então se diferenciar tanto em plasmócitos de vida longa, os quais produzem anticorpos de alta afinidade, como em células B de memória. Adaptado de Basso et al. 2015 (8).

\section{Ativação clássica de células B}

Células B apresentam receptores de reconhecimento de padrões moleculares (PRRs, do inglês Pattern Recognition Receptors), pertencentes ao grupo dos Receptores do tipo Toll (TLRs, do inglês Toll-like Receptors), que desempenham um papel crucial na ativação destas células (9). Grande parte dos TLRs sinalizam via a molécula adaptadora myeloid differentiation primary response 88 (MyD88). Entretanto TLR3 sinaliza apenas via TIR-domain-containing adapter-inducing interferon- $\beta$ (TRIF), enquanto que TLR4 sinaliza através de ambas proteínas (9). Em uma resposta T-independente, TLRs desempenham papel essencial na resposta 
humoral, como na produção de IgM. Por outro lado, em uma resposta T-dependente, TLRs atuam como adjuvantes $(10,11)$. Além do reconhecimento de patógenos por PRRs, células B apresentam em sua superfície receptores de células B (BCRs, do inglês B Cell Receptors), os quais são capazes de se ligarem diretamente a antígenos, promoverem sua endocitose e consequente apresentação para células T.

BCRs estão associados com as cadeias $\operatorname{Ig} \alpha$ e $\operatorname{Ig} \beta$, as quais estão também associadas ao Motivo de Ativação do Imunorreceptor Baseado em Tirosina (ITAM, do inglês Immunoreceptor Tyrosine-based Activation Motif) (12). Quando o BCR se liga a um antígeno multivalente ocorre a ativação de tirosina quinases da família do Src (Fyn, Blk e Lyn), que fosforilam os ITAMs. Os ITAMs fosforilados permitem a ligação da tirosina quinase Syk (12). Após isso, Syk ativada é capaz de fosforilar outros alvos como BLNK que, por sua vez, é capaz de ativar a Bruton's tyrosine kinase (Btk) (12). Btk pode então fosforilar a Fosfolipase $C \gamma$ (PLC- $\gamma$, do inglês Phospholipase $C$ ), a qual clivará Fosfatidilinositol-4,5-bisfosfato (PIP2, do inglês Phosphatidylinositol 4,5-bisphosphate) em Diacilglicerol (DAG) e Inositol 1,4,5trifosfato (IP3, do inglês Inositol 1,4,5-triphosphate) (12). Esta cascata levará a sinalização via cálcio e outras quinases que resultarão na ativação de fatores de transcrição e moléculas de expressão essenciais para proliferação e diferenciação de células B em plasmócitos, tais como Blimp1 e CD138 (12).

Sabe-se que Syk além de ativar BLNK, é também capaz de fosforilar o coreceptor de células B CD19 e o B-cell PI3K adaptor (BCAP), o que permite a ligação da quinase fosfoinositídeo 3-quinase (PI3K, do inglês Phosphoinositide 3-kinase) e sua posterior ativação $(13,14)$ (Figura 2). A ativação da quinase PI3K também ocorre após ativação de TLRs, embora o mecanismo ainda não esteja completamente elucidado.

A ativação da via PI3K/AKT em células B tem ganhado grande atenção devido ao papel crítico que exerce na atividade metabólica destas células (15). Por exemplo, a inibição de PI3K com o composto Ly294002 ou a deficiência em uma das subunidades de PI3K foi capaz de reduzir significativamente a expressão do transportador de glicose Glut1 e o transporte de glicose em células B após estímulo com anti-IgM (16). Atualmente, sabe-se que a ativação das células do sistema imune, incluindo as células $\mathrm{B}$, envolve mecanismos muito mais complexos do que a ativação clássica, como aqui anteriormente apresentada. Após a ativação das vias de 
sinalização de células B ocorrem também profundas alterações metabólicas, as quais são cuidadosamente reguladas por vias específicas como a de PI3K/AKT (15). O metabolismo celular não é apenas essencial para o crescimento e proliferação celular, mas é finamente regulado e capaz de ditar muitas das funções efetoras de células B. Trabalhos sugerem que a atividade mitocondrial e a síntese lipídica de células B, por exemplo, estão diretamente relacionadas à formação de plasmablastos/plasmócitos e produção de anticorpos $(17,18) .0$ impacto das vias metabólicas na função efetora de células do sistema imune e, consequentemente, no desfecho da resposta inflamatória tem ganhado grande relevância atualmente a ponto de ter se tornado uma nova área na Imunologia conhecida como Imunometabolismo.

\section{mTOR como sensor metabólico e seus impactos diretos na função imune de células B}

Como mencionado, a via PI3K/AKT é capaz de modular a atividade metabólica de células do sistema imune, isto ocorre por meio da ação de sensores metabólicos, como a proteína alvo da rapamicina (mTOR, em inglês Mechanistic Target of Rapamycin) $(19,20)$ (Figura 2).

mTOR, é uma serina treonina quinase descoberta após observação dos efeitos imunossupressores de um composto isolado de Streptomyces hygroscopicus, mais tarde chamado de rapamicina (21). Os esforços para a compreensão dos mecanismos de ação da rapamicina levaram a descoberta de mTOR, o qual é seu alvo principal $(22,23)$. mTOR é transcrito de um único gene, cujo produto proteico é componente central de dois complexos distintos, mTORC1 e mTORC2 (24). mTORC1 é composto por cinco subunidades: mTOR (unidade catalítica), regulatoryassociated protein of mTOR (Raptor); mammalian lethal with Sec13 protein8 (mLST8); the proline rich AKT substrate $40 \mathrm{kDa}$ (PRAS40); DEP-domain-containing mTOR-interacting protein (Deptor). Já mTORC2 é composto por seis subunidades: mTOR, rapamycin-insensitive companion of mTOR (Rictor); mammalian stressactivated protein kinase interacting protein (mSIN1); protein observed with Rictor-1 (Protor-1); mLST8; Deptor (24). A via do mTOR é capaz de integrar fatores ambientais para regular crescimento, proliferação e sobrevivência celular, tanto por 
meio do aumento da atividade glicolítica quanto da expressão de transportadores de aminoácidos nas células. $(25,26)$. Além disso, fatores de crescimento e citocinas podem ativar a molécula, bem como a ativação de células B por meio de TLRs e BCRs, como já mencionado (27) (Figura 2).

A ativação de mTORC1 é conhecida em maiores detalhes, enquanto a de mTORC2 ainda é pouco explorada (27). Com relação a mTORC1, sabe-se que a ativação de PI3K gera o mensageiro secundário PIP3, o qual pode ativar a Phosphoinositidedependent kinase-1 (PDK1) (28). PDK1 é então capaz de fosforilar AKT em seu sítio catalítico na Treonina 308 (T-loop-Tre308) (28) (Figura 2). A fosforilação de AKT leva a fosforilação e inativação do complexo da esclerose tuberosa (TSC, do inglês Tuberous Sclerosis Complex), regulador negativo de mTOR (29). Apesar da ativação de mTORC2 ser menos conhecida, o complexo, diferentemente de mTORC1, é também capaz de fosforilar AKT no sítio C-terminal hydrophobic motif na Serina 473 (HM-Ser473) $(30,31)$.

O papel exercido por mTOR, mais especificamente de mTORC1, em células B tem sido estudado desde 1990 com o uso do seu inibidor rapamicina. Os estudos iniciais mostraram que rapamicina é capaz de inibir a ativação de células B e impedir sua proliferação por uma variedade de estímulos, tais como anti-IgM, LPS, Fator ativador de células B (BAFF, do inglês B-cell-activating factor of the tumour-necrosisfactor Family) e anti-CD40 (32-35). Além disso, rapamicina foi capaz de inibir a formação de plasmócitos de vida curta, bem como a produção de anticorpos (36, 37). Entretanto, em outro estudo foi observado que células $B$ tratadas com rapamicina e incubadas com LPS ou LPS na presença de IL4, elevaram a frequência de células $B \operatorname{IgM}^{+}$(38). Além disso, foi relatado que o uso de rapamicina ou de animais contendo apenas células B deficientes de mTORC1 promoveu proteção contra diferentes cepas letais de Influenza devido a reatividade cruzada dos anticorpos após vacinação (38). Foi observado que estes animais não desenvolviam anticorpos IgG1 de alta afinidade como os animais controle, mas apresentavam altos níveis de anticorpos $\operatorname{IgM}$ de baixa afinidade, os quais foram capazes de eficientemente neutralizar cepas letais de Influenza (38). Este último trabalho destaca o impacto de mTORC1 em atuar negativamente na produção de IgM, cuja inibição da proteína foi capaz de promover proteção. 
Há também na literatura estudos que relatam o impacto da redução da atividade de mTORC2 em células B. É descrito que animais contendo células B deficientes de mTORC2 apresentavam capacidade de sobrevivência e de proliferação celular afetadas, bem como uma redução na geração de células produtoras de anticorpos e menores níveis de IgM e IgG após serem imunizados (39). Em contraste, em outro trabalho foi descrito que células B deficientes de mTORC2 não apresentavam alterações na sobrevivência, proliferação e nem na formação de plasmablastos após estímulo in vitro com LPS e elevavam a troca de isotipo de IgM para IgG1 (40). Dentre as explicações plausíveis para as diferenças encontras sobre o papel de mTORC2 no processo de ativação das células B estão os diferentes modelos animais utilizados pelos pesquisadores, e os níveis distintos de redução na atividade de mTORC2 em células B.

Como descrito, mTOR é capaz de controlar uma série de funções efetoras de células $B$, embora o mecanismo de ação nem sempre seja evidenciado. Por outro lado, há na literatura um número significativo de estudos, como os envolvendo células T, que reportam a ação de sensores metabólicos nas funções efetoras destas células por meio de alterações nas vias metabólicas $(27,41,42)$. Com base em estudos de células T é plausível levantar a hipótese de que as alterações na função efetora de células B decorrentes da atividade de mTOR sejam consequência de modificações provocadas por este sensor em suas vias metabólicas, uma vez que não há estudos detalhados que relatem o impacto de mTOR diretamente nas vias metabólicas de células B.

De modo geral, mTORC1 e mTORC2 possuem efeitos diretos nas vias metabólicas de células do sistema imune, sendo uma das mais impactadas a via glicolítica (43-45). 


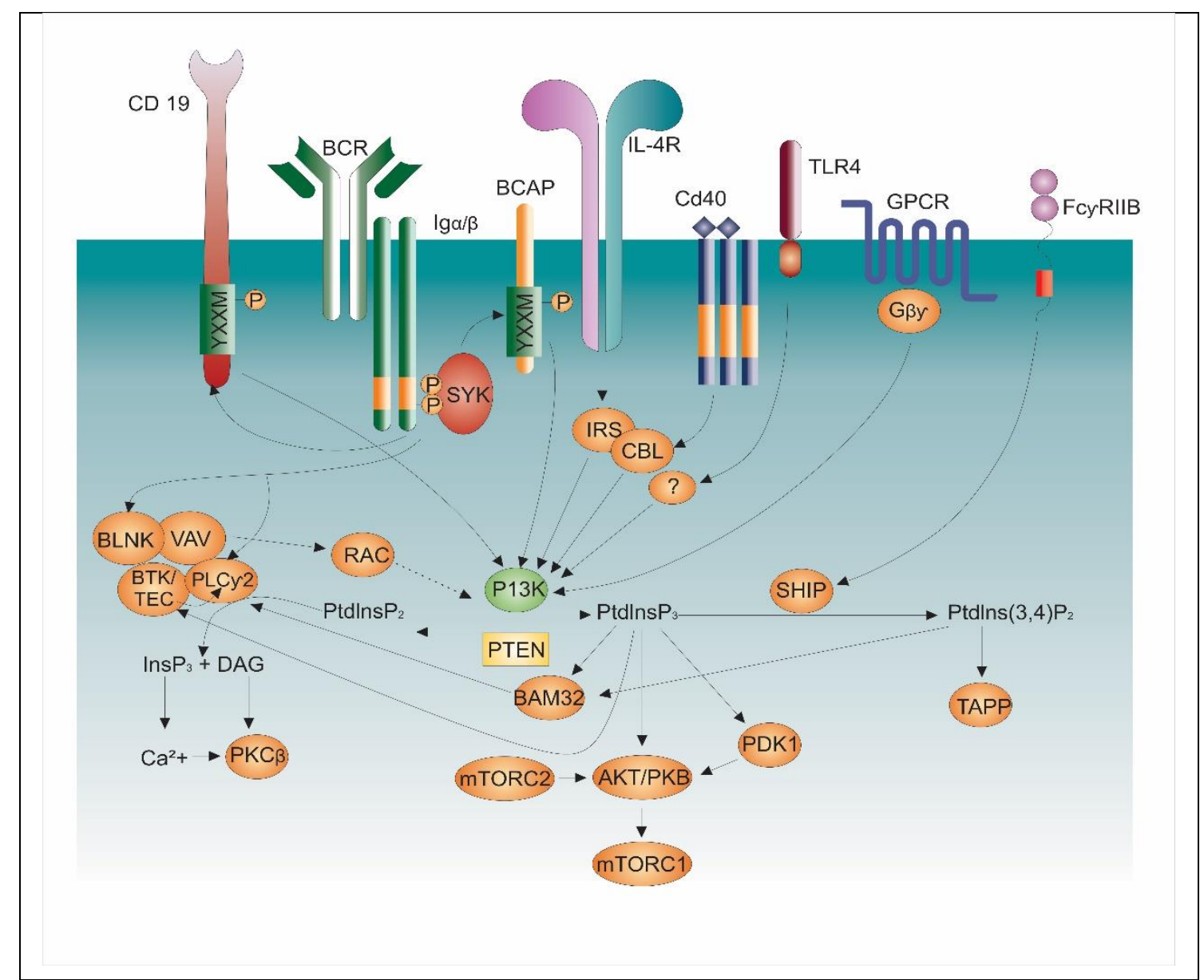

Figura 2 - Ativação da via PI3K-AKT-mTOR em células B. Representação da ativação da via PI3KAKT em células B. Células B podem ser ativadas de diferentes maneiras, como por meio da ligação de antígenos ao BCR ou reconhecimento de PAMPs por PRRs presentes nestas células. A ativação de PI3K via BCR não é completamente conhecida. Entretanto, sabe-se que pode ocorrer após ativação de BCR/Syk, o que leva a ativação de BLNK, o qual é capaz de fosforilar o co-receptor de células B CD19 e BCAP. A fosforilação de CD19 e BCAP pode ativar a quinase PI3K. Os mecanismos pelos quais PI3K é ativado via TLR4 também não são totalmente conhecidos. Após ativação, PI3K é capaz de gerar o mensageiro secundário PIP3, o qual pode ativar PDK1. PDK1 é, então, capaz de fosforilar AKT em seu sítio catalítico na Treonina 308. AKT pode ainda ser fosforilada por mTORC2 na Serina 473. A ativação de AKT por meio da fosforiação de seus sítios catalíticos é então capaz de ativar mTORC1. Adaptado de: Okkenhaugh \& Vanhaesebroeck, 2003 (19).

\section{Principais vias metabólicas em células B: glicólise aeróbica versus OXPHOS}

Várias vias metabólicas são essenciais para manter as atividades e funções das células do sistema imune, sendo que a glicólise e o ciclo do ácido tricarboxílico (TCA) são as mais conhecidas. A glicose é transportada para as células por meio de transportadores de glicose, como o GLUT1, principal transportador em linfócitos $(46,47)$. Cada molécula de glicose metabolizada pela via glicolítica gera duas moléculas de piruvato e um saldo positivo de duas moléculas de Adenosina trifosfato (ATP) (47). 0 piruvato pode ser transportado para a mitocôndria e iniciar 
o TCA para gerar diferentes fatores, entre eles $\mathrm{NADH}^{+}$e $\mathrm{FADH}_{2}{ }^{+}$, os quais podem transferir elétrons para a cadeia transportadora de elétrons e gerar um elevado número de moléculas de ATP pelo processo conhecido como fosforilação oxidativa (OXPHOS) (47). Por outro lado, para manutenção do fluxo glicolítico e de biossíntese, o piruvato pode ser reduzido à lactato, gerando um saldo positivo de duas moléculas de ATP e um elevado número de intermediários metabólicos, essenciais para síntese e proliferação celular. Este processo normalmente ocorre apenas na ausência de oxigênio (uma vez que ele é energeticamente desfavorável), sendo conhecido como fermentação $(47,48)$. Entretanto, a redução de piruvato a lactato pode ocorrer mesmo na presença de oxigênio. A escolha da célula em preferencialmente realizar glicólise em detrimento do TCA, mesmo na presença de oxigênio, é chamada de glicólise aeróbica ou Warburg Effect, inicialmente descrito em células tumorais (48) (Figura 3).

O TCA pode ainda ser alimentado pela oxidação de lipídeos e pela glutaminólise. Lipídeos de cadeia curta podem acessar passivamente a mitocôndria, enquanto lipídeos de cadeia média e longa necessitam primeiro ser conjugados à carnitina pela enzima mitocondrial Carnitine Palmitoyl Transferase I (CPT1a) (49). Uma vez localizados na mitocôndria estes lipídios podem ser oxidados por um processo conhecido como $\beta$-oxidação, o que gerará grande quantidade de acetil-CoA, $\mathrm{NADH}_{\text {e }} \mathrm{FADH}_{2}$ (50) (Figura 3).

Durante o TCA, o citrato é produzido e pode ser utilizado na síntese de lipídeos após seu transporte para o citoplasma. A enzima ATP cytrate lyase (ACLY) é a responsável pela conversão do citrato gerado na mitocôndria em acetil-CoA no citoplasma. Acetil-CoA pode então ser carboxilado e gerar malonil-CoA. Na sequência, a enzima Fatty Acid Synthase (FASN) pode então catalisar a elongação da crescente cadeia de lipídeos (51) (Figura 3). 


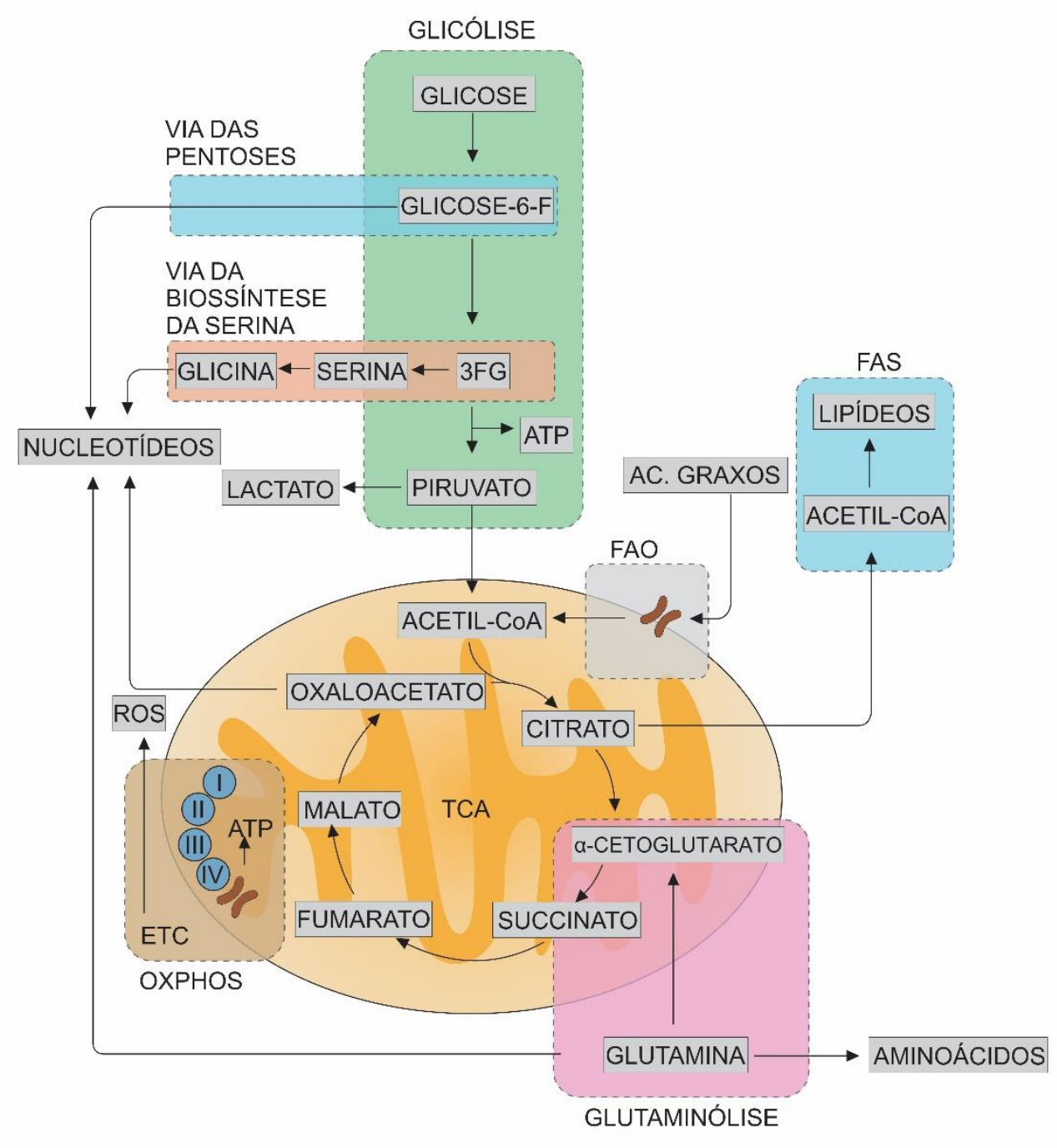

Figura 3 - Representação das principais vias metabólicas para geração de ATP em células B. 0 ATP pode ser gerado de diferentes formas, uma das mais eficientes é por meio do TCA e da cadeia respiratória de elétrons (OXPHOS) (áreas laranja e marrom, respectivamente). O TCA pode ser alimentado por diferentes vias, uma das mais comuns é por meio da glicólise (verde). A glicose, após capturada pela célula, pode entrar na via glicolítica e ser convertida em lactato, o que gerará um saldo positivo de apenas 2 ATPs. Por outro lado, o piruvato pode ser transportado do citoplasma para a mitocôndria, onde entrará no TCA (laranja) e ser convertido em acetyl-CoA. Durante o TCA será gerado uma série de agentes reduzidos, cujos elétrons serão utilizados para alimentar a OXPHOS (marrom), o que levará a um alto rendimento energético. Alternativamente a glicólise pode produzir uma série de intermediários que auxiliarão no crescimento e proliferação celular, como na produção de nucleotídeos por meio da via das pentoses e da biossíntese de serina, (azul e vermelho, respectivamente). 0 TCA pode ser alimentado ainda pela glutaminólise (roxo) e pela oxidação lipídica (cinza). Além disso, o TCA também pode suportar a síntese de aminoácidos por meio do oxaloacetato produzido, ou ainda a síntese lipídica (azul) por meio da conversão do citrato produzido no TCA em acetil-CoA no citoplasma. Adaptado de Buck et al. 2015 (41) 


\section{Vias metabólicas e seus impactos nas células B}

A ativação de células B leva a alterações metabólicas após interpretação de sinais presentes no meio, tais como citocinas e fatores de crescimento, por sensores metabólicos, como mTOR (27). Estes sinais determinam quais alterações metabólicas devem ocorrer afim de que as demandas das células recém ativadas sejam atendidas (27). Entretanto, os estudos sobre o controle de funções efetoras de células B por meio de alterações metabólicas desencadeadas pelo mTOR ainda são escassos. 0 impacto de mTOR nas vias metabólicas como causa de alterações na função efetora foi descrito em maiores detalhes em células T. Estas células, após ativação, elevam significativamente os níveis de glicólise aeróbica e de OXPHOS, com especial aumento nas taxas da primeira via $(52,53)$. Estudos apontam que o aumento da atividade glicolítica nestas células ocorre após ativação dos fatores de transcrição HIF1 $\alpha$ e MYC por mTORC1, os quais induzem a transcrição de genes relacionados a transportadores de glicose e da via glicolítica $(43,44)$. Pollizzi e colaboradores também reportaram que células T CD8+ deficientes de mTORC1 ou mTORC2 aumentam as taxas de OXPHOS, o que mostra que mTOR preferencialmente beneficia a glicólise aeróbica em detrimento da OXPHOS (54). Uma vez tendo ocorrido a eliminação do antígeno, a maior parte das células $\mathrm{T}$ efetoras morrem e uma subpopulação de células $\mathrm{T}$ de memória permanece. Esta subpopulação sobrevivente é especialmente dependente da atividade mitocondrial, em especial da oxidação lipídica para sua manutenção e não de glicólise aeróbica (55). Quando células T são impedidas de adotarem vias metabólicas específicas, como a glicólise aeróbica, sua diferenciação e função efetora podem ser afetadas, bem como o desfecho da resposta imune $(53,55)$.

Em células B, sabe-se que essas também passam por significativas alterações metabólicas, muitas das quais essenciais para suas funções efetoras, embora não tenha sido descrito o impacto de mTOR nestas vias. Células B, assim como células T, elevam significativamente os níveis de captação de glicose extracelular após ativação, a qual é metabolizada pela via glicolítica (56). Apesar de células B elevarem significativamente as taxas de glicólise aeróbica, estas células também elevam a OXPHOS a taxas similares, diferentemente de células $\mathrm{T}$ efetoras que priorizam apenas a glicólise aeróbica (56). A glicólise aeróbica tem sido apontada como 
fundamental para a proliferação e produção de anticorpos $(56,57)$. Por outro lado, já foi descrito que a diferenciação de células B em células produtoras de anticorpos é acompanhada por uma redução da atividade glicolítica e aumento no consumo de glutamina (18). Além disso, outro estudo apontou o papel essencial exercido pela glicose para a síntese lipídica, isto é, o aumento da importação de piruvato para a mitocôndria foi descrito como fundamental para a expansão de membranas, expressão de marcadores de plasmócitos, como CD138 e Blimp-1, e produção de anticorpos $(17,56)$. Estes resultados indicam que a dependência de vias metabólicas específicas antes, durante e após a ativação de células B são alteradas. Estes estudos destacam ainda uma dependência pronunciada da atividade mitocondrial e síntese lipídica para a formação de plasmablastos. Interessantemente, em estudo recente foi possível distinguir plasmócitos de vida curta e de vida longa por meio da definição do perfil metabólico apresentado por estas células. Plasmócitos de vida longa apresentam níveis aumentados de transporte de glicose com relação a plasmócitos de vida curta. $(58,59)$. Foi demonstrado que $90 \%$ da glicose capturada por plasmócitos de vida longa é destinada para glicosilação de anticorpos, por meio da via das hexosaminas (59). A via das hexosaminas é uma pequena ramificação da glicólise, capaz de fornecer açúcares utilizados para a glicosilação de proteínas e lipídeos (60). Entretanto, o restante capturado é crucial para a sobrevivência destas células por meio da geração e importação de piruvato para a mitocôndria (59). Desta maneira, mais estudos são necessários para melhor compreender os papéis exatos da glicólise aeróbica, de outras fontes de alimentação da mitocôndria e mesmo de OXPHOS em cada etapa da ativação de células B, como proliferação, diferenciação de plasmablastos/plasmócitos e produção de anticorpos.

Os estudos recentes de metabolismo em células B aproximaram suas funções efetoras de suas vias metabólicas (61). Desta maneira, alterações específicas nas vias metabólicas ou nas vias que as controlam como a via PI3K/AKT/mTOR podem beneficiar a resposta humoral e sobrevivência de plasmócitos. Com base nos trabalhos anteriormente apresentados é sabido que a deficiência de mTOR em células B beneficia OXPHOS em detrimento da glicólise aeróbica. Sabe-se também que a atividade mitocondrial é essencial para a diferenciação de células $B$ em plasmablastos. Desta maneira, a interferência na via do mTOR pode servir como uma nova estratégia para aumentar a resposta a patógenos e no desenvolvimento de 
vacinas por meio do aumento da formação de plasmócitos e produção de anticorpos. Por outro lado, as vias metabólicas também abrem porta para um melhor controle da resposta humoral, como por meio do uso de drogas que interfiram em pontos específicos destas vias, para que assim possam alterar o estado de ativação das células bem como a produção de anticorpos, beneficiando pacientes com doenças autoimunes e também pacientes transplantados. Anticorpos, por exemplo, continuam sendo um dos empecilhos para o sucesso na sobrevida de diversos transplantes (3). Desta maneira, a regulação de vias e de sensores metabólicos podem ser utilizados como uma nova abordagem no contexto de imunossupressão para controle da resposta humoral.

\section{Papel das células B e de vias metabólicas no contexto do transplante}

Transplantes são utilizados como tratamento para pacientes com diferentes complicações, normalmente falência de órgãos em estágio terminal, câncer e doenças autoimunes. 0 transplante consiste na transferência de células, tecidos ou órgãos de um indivíduo para outro que resulta em significativo aumento da sobrevida e da qualidade de vida do paciente transplantado $(62,63)$. No Brasil, segundo o Ministério da Saúde, no ano de 2016 o número de pacientes na lista de espera para receber um transplante de órgãos foi superior a 43.500. Além do alto número de pessoas na lista para receber um transplante, altos custos são gerados, especialmente com o uso de drogas imunossupressoras. Nos Estados Unidos, por exemplo, o custo anual médio em medicamentos prescritos no contexto do transplante está entre 10 e 14 mil dólares por paciente (64).

O processo de rejeição ao transplante pode ser classificado em três categorias, de acordo com a resposta imune efetora prioritária humoral e celular. São elas:

a) Rejeição hiperaguda: mediada por anticorpos naturais presentes no receptor. Também é possível que o receptor já tenha sido pré-sensibilizado com o Complexo Principal de Histocompatibilidade (MHC, do inglês Major Histocompatibility Complex) do doador por doações de sangue, gravidez, infecções ou transplantes anteriores, por exemplo. Essa rejeição pode ser observada em minutos ou horas após o transplante. 
b) Rejeição aguda: consiste no reconhecimento de tecido do doador como não próprio pelo sistema imune do receptor. Isso se deve principalmente a diferenças entre as moléculas de $\mathrm{MHC}$, as quais são extremamente polimórficas.

c) Rejeição crônica: caracterizada por uma perda lenta e gradual da função do órgão, com perda da arquitetura tecidual por fibrose. Uma explicação plausível é a ativação e infiltração de células T $\mathrm{CD}^{+}$e células $\mathrm{B}$, as quais ativam macrófagos e os estimulam a secretarem fatores de crescimento ativando e induzindo a diferenciação de miofibroblastos (65).

A falta de métodos apropriados para controlar a rejeição do órgão foi e continua sendo um dos maiores obstáculos para a manutenção dos aloenxertos, especialmente a longo prazo, apesar dos avanços obtidos com novas drogas imunossupressoras $(62,63,66)$. Portanto, o retransplante se faz necessário em um número significativo de casos. Grande parte das drogas imunossupressoras atuais visam reduzir a proliferação e atividade efetora de células T de maneira inespecífica, sendo elas as principais responsáveis pela rejeição aguda (67). 0 uso de drogas com interferência nas vias metabólicas, como a rapamicina, droga que interfere na atividade de mTOR, já são utilizadas na clínica há anos (68). Os maiores sucessos relacionados ao uso da rapamicina estão relacionados à redução de infecções e de câncer nos pacientes transplantados, uma vez que a droga é também capaz de interferir na proliferação de células tumorais (68-71). Entretanto, novas abordagem para diminuir as taxas de rejeição e com enfoque na redução dos efeitos adversos das drogas imunossupressoras clássicas são necessárias, uma nova alternativa consiste em explorar as vias metabólicas e/ou seus sensores de maneira mais específica e eficiente que apenas o uso da rapamicina (72).

Como descrito nas seções anteriores, o controle das vias metabólicas é crucial para modificar o curso das respostas imunes (55). De modo interessante, um estudo recente utilizou uma terapia tripla em modelos experimentais de transplante de pele e de coração, cujo regime de drogas interfere negativamente na via glicolítica e na glutaminólise (73). Constatou-se neste estudo um aumento significativo na sobrevida dos transplantes de pele e de coração, o que esteve relacionado a uma expansão de células T reguladoras e diminuição de células T efetoras (73). 
Como citado anteriormente, apesar dos grandes avanços no controle de rejeição aos transplantes, ainda aproximadamente $20 \%$ dos pacientes na lista de espera para receber um transplante renal já foram transplantados anteriormente e necessitam de um novo órgão devido à perda do aloenxerto causada por rejeição (74). De modo importante, estes pacientes são sensibilizados por antígenos presentes no doador anterior e apresentam, portanto, anticorpos específicos anti-doador (DAS, do inglês Donor Specific Antibodies)(74). Células B apresentam um papel significativo no processo de rejeição, o qual é classicamente associado com a produção de DSA (3, $75,76)$. De modo geral, células B são caracterizadas por uma mobilização e ativação não apropriadamente controladas após o transplante (75). É conhecida a especificidade de grande parte dos aloanticorpos produzidos, sendo estes principalmente contra as moléculas do MHC presentes no aloenxerto, ou ainda pela presença de DSA pré-formados nos casos de sensibilização prévia ao antígeno (77). O National Institute of Health caracterizou as etapas da rejeição mediada por anticorpos em quatro estágios (78). Estágio I, geração de novo de anticorpos reativos contra o enxerto. Estágio II, fixação e ativação do complemento no enxerto, sem a presença de sinais de danos patológicos e/ou clínicos. Estágio III, além da fixação do complemento observado no estágio anterior, ocorre alterações patológicas no enxerto, embora suas funções estejam preservadas. Finalmente, no estágio IV, além da fixação do complemento e de danos patológicos observados, ocorre a disfunção do enxerto.

Com o objetivo de melhor avaliar o papel desempenhado por anticorpos no contexto da rejeição, Wasowska et al utilizaram um modelo de transplante cardíaco alogênico em camundongos deficientes para Imunoglobulina (IgKO). Estes apresentaram taxas de sobrevida do enxerto significativamente maiores em relação a animais controle (76). Foi mostrado ainda que a transferência de IgG2b foi capaz de reconstituir a rejeição aguda em animais IgKO (76). Os DSA podem levar a fixação do sistema complemento e elevar desta maneira a probabilidade de rejeição ao aloenxerto $(3,75)$. Sabe-se que a presença de anticorpos incapazes de fixarem o complemento facilitam a acomodação do enxerto e evitam sua rejeição e que reguladores do complemento são capazes de impedir rejeição hiperaguda mediada por anticorpos $(79,80)$. Desta maneira, estes resultados indicam o papel crítico desempenhado por anticorpos, por meio da fixação do complemento na rejeição 
hiperaguda e aguda mediada por anticorpos, além de representarem um empecilho para realização de retransplantes.

Tendo em vista o papel crucial desempenhado por células B no contexto do transplante, há uma urgente necessidade de se descobrirem novas estratégias terapêuticas, tais como alvos que participem da fisiopatologia da rejeição de modo a promover a aceitação do órgão recém recebido e de controlar a resposta imune humoral. 0 estudo de Lee e colaboradores, 2015 por meio de uma terapia tripa, cujos alvos foram as vias metabólicas, representou um novo horizonte para o desenvolvimento de drogas imunossupressoras (73). Entretanto, estudos direcionados ao controle de células $\mathrm{B}$ e de sua diferenciação em plasmablastos e plasmócitos, a fim de controlar a resposta imune humoral ainda são necessários

\section{Justificativa}

A regulação precisa do estado de ativação de células B é essencial para controlar a produção de anticorpos e, consequentemente, determinar o desfecho da resposta imune. Entretanto, apesar dos avanços obtidos sobre o conhecimento e o controle da resposta humoral, as opções disponíveis para modular efetivamente a resposta de células $\mathrm{B}$ em diversas doenças inflamatórias permanecem pouco significativas. Atualmente, a dinâmica das vias metabólicas em células do sistema imune tem sido bastante explorada, sendo o metabolismo em si um potencial alvo para o desenvolvimento de novas abordagens terapêuticas. Sabe-se que as vias metabólicas não estão apenas envolvidas no crescimento e proliferação celular, mas estão intimamente relacionadas com a função efetora das células do sistema imune e que toda esta rede metabólica é amplamente regulada por sensores metabólicos intracelulares. Embora estudos descrevam as alterações metabólicas envolvidas no processo de ativação de células $B$, existem poucos relatos sobre quais sensores metabólicos coordenam estes processos, bem como suas possíveis implicações na diferenciação destas células em plasmócitos. O sensor metabólico mTOR tem mostrado ser um regulador mestre sobre o metabolismo de células T, promovendo a glicólise aeróbica em detrimento da oxidação lipídica e OXPHOS e é um potencial candidato para atuar em diferentes etapas de ativação de células B. Acredita-se que a compreensão deste processo auxiliará o desenvolvimento de novas estratégias 
que visem controlar a resposta imune humoral, auxiliando pacientes com doenças inflamatórias mediadas por células B, como em certas infecções, doenças autoimunes e em pacientes transplantados. 


\section{CONCLUSÕES}

Nossos resultados indicam que:

- mTORC2 favorece a glicólise aeróbica em detrimento de OXPHOS, prejudicando a ativação de células B e sua diferenciação em plasmablastos. Por outro lado, mTORC2 eleva a atividade mitocondrial de plasmablastos e a secreção de anticorpos.

- mTORC1 favorece a glicólise aeróbica, prejudicando a ativação de células B e sua diferenciação em plasmablastos. 


\section{REFERÊNCIAS*}

1. Hiepe F, Dörner $T$, Hauser AE, Hoyer BF, Mei H, Radbruch A. Long-lived autoreactive plasma cells drive persistent autoimmune inflammation. Nat Rev Rheumatol. 2011;7(3):170-8.

2. Dörner T, Radbruch A. Antibodies and B cell memory in viral immunity. Immunity. 2007;27(3):384-92.

3. Kokko KE, Colvin RB. Below the waterline -- the danger of de novo donor-specific HLA antibodies. Am J Transplant. 2012;12(5):1077-8.

4. Nutt SL, Hodgkin PD, Tarlinton DM, Corcoran LM. The generation of antibody-secreting plasma cells. Nat Rev Immunol. 2015;15(3):160-71.

5. $\quad$ Allman D, Pillai S. Peripheral B cell subsets. Curr Opin Immunol. 2008;20(2):149-57.

6. MacLennan IC, Toellner KM, Cunningham AF, Serre K, Sze DM, Zúñiga E, et al. Extrafollicular antibody responses. Immunol Rev. 2003;194:8-18.

7. Radbruch A, Muehlinghaus G, Luger EO, Inamine A, Smith KG, Dörner T, et al. Competence and competition: the challenge of becoming a long-lived plasma cell. Nat Rev Immunol. 2006;6(10):741-50.

8. Basso K, Dalla-Favera R. Germinal centres and B cell lymphomagenesis. Nat Rev Immunol. 2015;15(3):172-84.

9. Hua Z, Hou B. TLR signaling in B-cell development and activation. Cell Mol Immunol. 2013;10(2):103-6.

10. Alugupalli KR, Akira S, Lien E, Leong JM. MyD88- and Bruton's tyrosine kinase-mediated signals are essential for $\mathrm{T}$ cell-independent pathogen-specific IgM responses. J Immunol. 2007;178(6):3740-9.

11. Hou B, Saudan P, Ott G, Wheeler ML, Ji M, Kuzmich L, et al. Selective utilization of Tolllike receptor and MyD88 signaling in B cells for enhancement of the antiviral germinal center response. Immunity. 2011;34(3):375-84.

12. Kurosaki T, Shinohara H, Baba Y. B cell signaling and fate decision. Annu Rev Immunol. 2010;28:21-55.

13. Okada T, Maeda A, Iwamatsu A, Gotoh K, Kurosaki T. BCAP: the tyrosine kinase substrate that connects $B$ cell receptor to phosphoinositide 3-kinase activation. Immunity. 2000;13(6):817-27.

14. Tuveson DA, Carter RH, Soltoff SP, Fearon DT. CD19 of B cells as a surrogate kinase insert region to bind phosphatidylinositol 3-kinase. Science. 1993;260(5110):986-9.

15. Jellusova J, Rickert RC. The PI3K pathway in B cell metabolism. Crit Rev Biochem Mol Biol. 2016;51(5):359-78.

16. Doughty CA, Bleiman BF, Wagner DJ, Dufort FJ, Mataraza JM, Roberts MF, et al. Antigen receptor-mediated changes in glucose metabolism in $B$ lymphocytes: role of phosphatidylinositol 3-kinase signaling in the glycolytic control of growth. Blood. 2006;107(11):4458-65.

17. Dufort FJ, Gumina MR, Ta NL, Tao Y, Heyse SA, Scott DA, et al. Glucose-dependent de novo lipogenesis in $B$ lymphocytes: a requirement for atp-citrate lyase in lipopolysaccharideinduced differentiation. J Biol Chem. 2014;289(10):7011-24.

18. Garcia-Manteiga JM, Mari S, Godejohann M, Spraul M, Napoli C, Cenci S, et al. Metabolomics of B to plasma cell differentiation. J Proteome Res. 2011;10(9):4165-76.

19. Okkenhaug K, Vanhaesebroeck B. PI3K in lymphocyte development, differentiation and activation. Nat Rev Immunol. 2003;3(4):317-30.

20. Shimobayashi M, Hall MN. Making new contacts: the mTOR network in metabolism and signalling crosstalk. Nat Rev Mol Cell Biol. 2014;15(3):155-62.

*Referência Estilo Vancouver 
21. Dennis PB, Fumagalli S, Thomas G. Target of rapamycin (TOR): balancing the opposing forces of protein synthesis and degradation. Curr Opin Genet Dev. 1999;9(1):49-54.

22. Schmelzle T, Hall MN. TOR, a central controller of cell growth. Cell. 2000;103(2):253-62. 23. Heitman J, Movva NR, Hall MN. Targets for cell cycle arrest by the immunosuppressant rapamycin in yeast. Science. 1991;253(5022):905-9.

24. Laplante M, Sabatini DM. mTOR signaling at a glance. J Cell Sci. 2009;122(Pt 20):3589-

94.

25. Maclver NJ, Michalek RD, Rathmell JC. Metabolic regulation of T lymphocytes. Annu Rev Immunol. 2013;31:259-83.

26. Tokunaga C, Yoshino K, Yonezawa K. mTOR integrates amino acid- and energy-sensing pathways. Biochem Biophys Res Commun. 2004;313(2):443-6.

27. Powell JD, Delgoffe GM. The mammalian target of rapamycin: linking $T$ cell differentiation, function, and metabolism. Immunity. 2010;33(3):301-11.

28. Alessi DR, James SR, Downes CP, Holmes $A B$, Gaffney PR, Reese $C B$, et al. Characterization of a 3-phosphoinositide-dependent protein kinase which phosphorylates and activates protein kinase Balpha. Curr Biol. 1997;7(4):261-9.

29. Saucedo L, Gao X, Chiarelli DA, Li L, Pan D, Edgar BA. Rheb promotes cell growth as a component of the insulin/TOR signalling network. Nat Cell Biol. 2003;5(6):566-71.

30. Jacinto E, Facchinetti V, Liu D, Soto N, Wei S, Jung SY, et al. SIN1/MIP1 maintains rictormTOR complex integrity and regulates Akt phosphorylation and substrate specificity. Cell. 2006;127(1):125-37.

31. Sarbassov DD, Guertin DA, Ali SM, Sabatini DM. Phosphorylation and regulation of Akt/PKB by the rictor-mTOR complex. Science. 2005;307(5712):1098-101.

32. Wicker LS, Boltz RC, Matt V, Nichols EA, Peterson LB, Sigal NH. Suppression of B cell activation by cyclosporin A, FK506 and rapamycin. Eur J Immunol. 1990;20(10):2277-83.

33. Kay JE, Kromwel L, Doe SE, Denyer M. Inhibition of T and B lymphocyte proliferation by rapamycin. Immunology. 1991;72(4):544-9.

34. Sakata A, Kuwahara K, Ohmura T, Inui S, Sakaguchi N. Involvement of a rapamycinsensitive pathway in CD40-mediated activation of murine B cells in vitro. Immunol Lett. 1999;68(2-3):301-9.

35. Zeng Q, Zhang H, Qin J, Xu Z, Gui L, Liu B, et al. Rapamycin inhibits BAFF-stimulated cell proliferation and survival by suppressing mTOR-mediated PP2A-Erk1/2 signaling pathway in normal and neoplastic B-lymphoid cells. Cell Mol Life Sci. 2015;72(24):4867-84.

36. Aagaard-Tillery KM, Jelinek DF. Inhibition of human B lymphocyte cell cycle progression and differentiation by rapamycin. Cell Immunol. 1994;156(2):493-507.

37. Jones DD, Gaudette BT, Wilmore JR, Chernova I, Bortnick A, Weiss BM, et al. mTOR has distinct functions in generating versus sustaining humoral immunity. J Clin Invest. 2016;126(11):4250-61.

38. Keating R, Hertz T, Wehenkel M, Harris TL, Edwards BA, McClaren JL, et al. The kinase mTOR modulates the antibody response to provide cross-protective immunity to lethal infection with influenza virus. Nat Immunol. 2013;14(12):1266-76.

39. Lee K, Heffington L, Jellusova J, Nam KT, Raybuck A, Cho SH, et al. Requirement for Rictor in homeostasis and function of mature B lymphoid cells. Blood. 2013;122(14):2369-79.

40. Limon JJ, So L, Jellbauer S, Chiu H, Corado J, Sykes SM, et al. mTOR kinase inhibitors promote antibody class switching via mTORC2 inhibition. Proc Natl Acad Sci U S A. 2014;111(47):E5076-85.

41. Buck MD, O'Sullivan D, Pearce EL. T cell metabolism drives immunity. J Exp Med. 2015;212(9):1345-60.

42. Buck MD, Sowell RT, Kaech SM, Pearce EL. Metabolic Instruction of Immunity. Cell. 2017;169(4):570-86. 
43. Shi LZ, Wang R, Huang G, Vogel P, Neale G, Green DR, et al. HIF1alpha-dependent glycolytic pathway orchestrates a metabolic checkpoint for the differentiation of TH17 and Treg cells. J Exp Med. 2011;208(7):1367-76.

44. Wang R, Dillon CP, Shi LZ, Milasta S, Carter R, Finkelstein D, et al. The transcription factor Myc controls metabolic reprogramming upon $T$ lymphocyte activation. Immunity. 2011;35(6):871-82.

45. Masui K, Tanaka K, Akhavan D, Babic I, Gini B, Matsutani T, et al. mTOR complex 2 controls glycolytic metabolism in glioblastoma through FoxO acetylation and upregulation of cMyc. Cell Metab. 2013;18(5):726-39.

46. Wieman HL, Wofford JA, Rathmell JC. Cytokine stimulation promotes glucose uptake via phosphatidylinositol-3 kinase/Akt regulation of Glut1 activity and trafficking. Mol Biol Cell. 2007;18(4):1437-46.

47. O'Neill LA, Kishton RJ, Rathmell J. A guide to immunometabolism for immunologists. Nat Rev Immunol. 2016;16(9):553-65.

48. Vander Heiden MG, Cantley LC, Thompson CB. Understanding the Warburg effect: the metabolic requirements of cell proliferation. Science. 2009;324(5930):1029-33.

49. Ramsay RR, Zammit VA. Carnitine acyltransferases and their influence on CoA pools in health and disease. Mol Aspects Med. 2004;25(5-6):475-93.

50. Currie E, Schulze A, Zechner R, Walther TC, Farese RV. Cellular fatty acid metabolism and cancer. Cell Metab. 2013;18(2):153-61.

51. Ohlrogge JB, Jaworski JG. REGULATION OF FATTY ACID SYNTHESIS. Annu Rev Plant Physiol Plant Mol Biol. 1997;48:109-36.

52. Sena LA, Li S, Jairaman A, Prakriya M, Ezponda T, Hildeman DA, et al. Mitochondria are required for antigen-specific $T$ cell activation through reactive oxygen species signaling. Immunity. 2013;38(2):225-36.

53. Chang $\mathrm{CH}$, Curtis JD, Maggi LB, Faubert B, Villarino AV, O'Sullivan $\mathrm{D}$, et al. Posttranscriptional control of $T$ cell effector function by aerobic glycolysis. Cell. 2013;153(6):1239-51.

54. Pollizzi KN, Patel $\mathrm{CH}$, Sun $\mathrm{IH}$, Oh MH, Waickman AT, Wen J, et al. mTORC1 and mTORC2 selectively regulate CD8 ${ }^{+} \mathrm{T}$ cell differentiation. J Clin Invest. 2015;125(5):2090-108.

55. Pearce EL, Poffenberger $\mathrm{MC}$, Chang $\mathrm{CH}$, Jones RG. Fueling immunity: insights into metabolism and lymphocyte function. Science. 2013;342(6155):1242454.

56. Caro-Maldonado A, Wang R, Nichols AG, Kuraoka M, Milasta S, Sun LD, et al. Metabolic reprogramming is required for antibody production that is suppressed in anergic but exaggerated in chronically BAFF-exposed B cells. J Immunol. 2014;192(8):3626-36.

57. Milasta S, Dillon CP, Sturm OE, Verbist KC, Brewer TL, Quarato G, et al. ApoptosisInducing-Factor-Dependent Mitochondrial Function Is Required for $\mathrm{T}$ Cell but Not B Cell Function. Immunity. 2016;44(1):88-102.

58. Corcoran LM, Nutt SL. Long-Lived Plasma Cells Have a Sweet Tooth. Immunity. 2016;45(1):3-5.

59. Lam WY, Becker AM, Kennerly KM, Wong R, Curtis JD, Llufrio EM, et al. Mitochondrial Pyruvate Import Promotes Long-Term Survival of Antibody-Secreting Plasma Cells. Immunity. 2016;45(1):60-73.

60. Buse MG. Hexosamines, insulin resistance, and the complications of diabetes: current status. Am J Physiol Endocrinol Metab. 2006;290(1):E1-E8.

61. Boothby M, Rickert RC. Metabolic Regulation of the Immune Humoral Response. Immunity. 2017;46(5):743-55.

62. Ireland R. Renal transplantation: Making kidneys count. Nat Rev Nephrol. 2012;8(6):311.

63. Baran DA. New directions in immunosuppression after heart transplantation. Nat Rev Cardiol. 2013;10(7):422-7.

64. James A, Mannon RB. The Cost of Transplant Immunosuppressant Therapy: Is This Sustainable? Curr Transplant Rep. 2015;2(2):113-21. 
65. Moraes-Vieira PM, Silva HM, Takenaka MC, Monteiro SM, Lemos F, Saitovitch D, et al. Differential monocyte STAT6 activation and CD4(+)CD25(+)Foxp3(+) T cells in kidney operational tolerance transplanted individuals. Hum Immunol. 2010;71(5):442-50.

66. Longnus SL, Mathys V, Dornbierer M, Dick F, Carrel TP, Tevaearai HT. Heart transplantation with donation after circulatory determination of death. Nat Rev Cardiol. 2014;11(6):354-63.

67. Issa F, Schiopu A, Wood KJ. Role of $T$ cells in graft rejection and transplantation tolerance. Expert Rev Clin Immunol. 2010;6(1):155-69.

68. Fantus D, Rogers NM, Grahammer F, Huber TB, Thomson AW. Roles of mTOR complexes in the kidney: implications for renal disease and transplantation. Nat Rev Nephrol. 2016;12(10):587-609.

69. Nashan B, Gaston R, Emery V, Säemann MD, Mueller NJ, Couzi L, et al. Review of cytomegalovirus infection findings with mammalian target of rapamycin inhibitor-based immunosuppressive therapy in de novo renal transplant recipients. Transplantation. 2012;93(11):1075-85.

70. Tedesco-Silva H, Felipe C, Ferreira A, Cristelli M, Oliveira N, Sandes-Freitas T, et al. Reduced Incidence of Cytomegalovirus Infection in Kidney Transplant Recipients Receiving Everolimus and Reduced Tacrolimus Doses. Am J Transplant. 2015;15(10):2655-64.

71. Knoll GA, Kokolo MB, Mallick R, Beck A, Buenaventura CD, Ducharme R, et al. Effect of sirolimus on malignancy and survival after kidney transplantation: systematic review and metaanalysis of individual patient data. BMJ. 2014;349:g6679.

72. Bettencourt IA, Powell JD. Targeting Metabolism as a Novel Therapeutic Approach to Autoimmunity, Inflammation, and Transplantation. J Immunol. 2017;198(3):999-1005.

73. Lee CF, Lo YC, Cheng CH, Furtmüller GJ, Oh B, Andrade-Oliveira V, et al. Preventing Allograft Rejection by Targeting Immune Metabolism. Cell Rep. 2015;13(4):760-70.

74. Ott $U$, Busch $M$, Steiner $T$, Schubert J, Wolf $G$. Renal retransplantation: a retrospective monocentric study. Transplant Proc. 2008;40(5):1345-8.

75. Coelho V, Saitovitch D, Kalil J, Silva HM. Rethinking the multiple roles of B cells in organ transplantation. Curr Opin Organ Transplant. 2013;18(1):13-21.

76. Wasowska BA, Qian Z, Cangello DL, Behrens E, Van Tran K, Layton J, et al. Passive transfer of alloantibodies restores acute cardiac rejection in IgKO mice. Transplantation. 2001;71(6):72736.

77. Del Bello A, Congy-Jolivet N, Muscari F, Lavayssiere L, Esposito L, Cardeau-Desangles I, et al. Prevalence, incidence and risk factors for donor-specific anti-HLA antibodies in maintenance liver transplant patients. Am J Transplant. 2014;14(4):867-75.

78. Colvin RB, Smith RN. Antibody-mediated organ-allograft rejection. Nat Rev Immunol. 2005;5(10):807-17.

79. Mohiuddin MM, Ogawa H, Yin DP, Shen J, Galili U. Antibody-mediated accommodation of heart grafts expressing an incompatible carbohydrate antigen. Transplantation. 2003;75(3):258-62.

80. Ménoret S, Plat $M$, Blancho G, Martinat-Botté F, Bernard $P$, Karam $G$, et al. Characterization of human CD55 and CD59 transgenic pigs and kidney xenotransplantation in the pig-to-baboon combination. Transplantation. 2004;77(9):1468-71.

81. Rickert RC, Roes J, Rajewsky K. B lymphocyte-specific, Cre-mediated mutagenesis in mice. Nucleic Acids Res. 1997;25(6):1317-8.

82. Rickert RC, Rajewsky K, Roes J. Impairment of T-cell-dependent B-cell responses and B1 cell development in CD19-deficient mice. Nature. 1995;376(6538):352-5.

83. van der Windt GJ, Chang CH, Pearce EL. Measuring Bioenergetics in T Cells Using a Seahorse Extracellular Flux Analyzer. Curr Protoc Immunol. 2016;113:3.16B.1-3.B.4.

84. Choi SW, Gerencser AA, Nicholls DG. Bioenergetic analysis of isolated cerebrocortical nerve terminals on a microgram scale: spare respiratory capacity and stochastic mitochondrial failure. J Neurochem. 2009;109(4):1179-91. 
85. van der Windt GJ, Everts B, Chang CH, Curtis JD, Freitas TC, Amiel E, et al. Mitochondrial respiratory capacity is a critical regulator of CD8+ T cell memory development. Immunity. 2012;36(1):68-78.

86. Yadava N, Nicholls DG. Spare respiratory capacity rather than oxidative stress regulates glutamate excitotoxicity after partial respiratory inhibition of mitochondrial complex I with rotenone. J Neurosci. 2007;27(27):7310-7.

87. Dufort FJ, Bleiman BF, Gumina MR, Blair D, Wagner DJ, Roberts MF, et al. Cutting edge: IL-4-mediated protection of primary B lymphocytes from apoptosis via Stat6-dependent regulation of glycolytic metabolism. J Immunol. 2007;179(8):4953-7.

88. Reales-Calderón JA, Aguilera-Montilla N, Corbí Á, Molero G, Gil C. Proteomic characterization of human proinflammatory M1 and anti-inflammatory M2 macrophages and their response to Candida albicans. Proteomics. 2014;14(12):1503-18.

89. Zhong D, Xiong L, Liu T, Liu X, Chen J, Sun SY, et al. The glycolytic inhibitor 2-deoxyglucose activates multiple prosurvival pathways through IGF1R. J Biol Chem. 2009;284(35):23225-33.

90. Suzuki A, Kaisho T, Ohishi M, Tsukio-Yamaguchi M, Tsubata T, Koni PA, et al. Critical roles of Pten in B cell homeostasis and immunoglobulin class switch recombination. J Exp Med. 2003;197(5):657-67.

91. Sernández IV, de Yébenes VG, Dorsett $Y$, Ramiro AR. Haploinsufficiency of activationinduced deaminase for antibody diversification and chromosome translocations both in vitro and in vivo. PLoS One. 2008;3(12):e3927.

92. Omori SA, Cato MH, Anzelon-Mills A, Puri KD, Shapiro-Shelef M, Calame K, et al. Regulation of class-switch recombination and plasma cell differentiation by phosphatidylinositol 3-kinase signaling. Immunity. 2006;25(4):545-57.

93. Lazorchak AS, Liu D, Facchinetti V, Di Lorenzo A, Sessa WC, Schatz DG, et al. Sin1mTORC2 suppresses rag and il7r gene expression through Akt2 in B cells. Mol Cell. 2010;39(3):433-43.

94. Gerlag PG, Koene RA, Hagemann JF, Wijdeveld PG. Hyperacute rejection of skin allografts in the mouse. Sensitivity of ingrowing skin grafts to the action of alloantibody and rabbit complement. Transplantation. 1975;20(4):308-13.

95. Jooste SV, Colvin RB, Soper WD, Winn HJ. The vascular bed as the primary target in the destruction of skin grafts by antiserum. I. Resistance of freshly placed xenografts of skin to antiserum. J Exp Med. 1981;154(5):1319-31. 